\title{
DESENVOLVIMENTO, CARACTERIZAÇÃO E ESTABILIDADE DE GELEIA TRADICIONAL DE UMBU-CAJÁ ${ }^{1}$
}

\author{
EMANUEL NETO ALVES DE OLIVEIRA ${ }^{2}$, DYEGO DA COSTA SANTOS ${ }^{2}$, \\ ANA PAULA TRINDADE ROCHA ${ }^{3}$, JOSIVANDA PALMEIRA GOMES ${ }^{4}$
}

RESUMO - Objetivou-se desenvolver geleia tradicional de umbu-cajá, caracterizá-la quanto a parâmetros físicos, químicos, microbiológicos e sensoriais, e avaliar sua estabilidade durante o armazenamento por seis meses em condições ambientais. Para processamento, foram utilizados $44 \%$ de polpa diluída de umbu-cajá, $1 \%$ de pectina de alto teor de metoxilação (ATM) e $55 \%$ de açúcar cristal. A formulação foi submetida à cocção em tacho aberto de aço inoxidável até teor de sólidos solúveis totais de cerca de $68^{\circ}$ Brix. A geleia foi envasada em recipientes de vidros transparentes, caracterizada e estocada em temperatura e umidade relativa médias de $23,25{ }^{\circ} \mathrm{C}$ e $81 \%$, respectivamente, com acompanhamento por meio de análises físicas e químicas a cada 30 dias de armazenamento. Os resultados da caracterização química evidenciaram produto com elevado teor de carboidratos, baixos conteúdos de cinzas e proteínas e valor calórico de $256 \mathrm{kcal} / 100$ g. Não foi verificado contagem dos microorganismos pesquisados (bolores e leveduras, coliformes totais e termotolerantes, Staphylococcus, bactérias mesófilas e Salmonella). Constatou-se alta aceitabilidade, com índices de aceitação superiores a 70\% para todos os atributos sensoriais investigados (cor, aparência, aroma, consistência, sabor, doçura e impressão global) e intenção de compra de $67,5 \%$, indicando potencial para industrialização e comercialização. $\mathrm{O}$ armazenamento promoveu aumento significativo nos valores de $\mathrm{pH}$, sólidos solúveis totais (SST), relação SST/ATT e firmeza e reduções significativas na acidez total titulável (ATT), atividade de água, luminosidade, intensidades de vermelho e amarelo, croma, ângulo de tonalidade, extrusão e adesividade. Constatou-se tendência à estabilidade dos valores de umidade e de sólidos totais. $\mathrm{O}$ processamento do umbu-cajá para elaboração de geleia mostrou-se viável, apresentando-se como mais uma opção de renda para pequenos produtores do semiárido brasileiro.

Termos para indexação: Spondias spp., processamento, controle de qualidade, estocagem.

\section{DEVELOPMENT, CHARACTERIZATION AND STABILITY OF TRADITIONAL UMBU-CAJA JAM}

\begin{abstract}
The aim of this study was to develop traditional umbu-caja jam, characterization of its physical, chemical, microbiological and sensory parameters, and to evaluate the stability during storage for six months at ambient conditions. For processing, $44 \%$ of the diluted umbu-caja pulp, $1 \%$ of high methoxyl pectin (HMP) and $55 \%$ of granulated sugar were used. The formulation was subjected to cooking in open stainless steel pan until soluble solids content of about $68^{\circ}$ Brix. The jam was bottled in transparent glass containers. It was characterized and stored in temperature and humidity averages of $23.25{ }^{\circ} \mathrm{C}$ and $81 \%$ respectively with monitoring by physical and chemical analysis at every 30 days of storage. The results of the chemical characterization showed that product presented high carbohydrate content, low protein and ash contents and calorific value of $256 \mathrm{~g} \mathrm{kcal} / 100 \mathrm{~g}$. It was not observed any microorganisms in this product (molds and yeasts, total and thermotolerants coliforms, Staphylococcus, Salmonella and mesophilic bacteria). There was a high acceptability, with acceptance rates greater than $70 \%$ for all investigated sensory attributes (color, appearance, aroma, consistency, taste, sweetness and overall impression) and purchase intent of $67.5 \%$, indicating a potential for industrialization and marketing. The storage caused a significant increase in $\mathrm{pH}$, total soluble solids (TSS), TSS/TA ratio and firmness, and significant reductions in titratable acidity (TA), water activity, lightness $\left(\mathrm{L}^{*}\right)$, intensities of red $\left(\mathrm{a}^{*}\right)$ and of yellow $\left(\mathrm{b}^{*}\right)$ colors, chroma $\left(\mathrm{c}^{*}\right)$, hue angle $\left(\mathrm{h}^{*}\right)$, extrusion and adhesiveness. There was a tendency for stability of moisture and total solids. The processing of umbu-caja for preparation of jam was feasible, presenting itself as another option of income for small farmers in the Brazilian semiarid.
\end{abstract}

Index terms: Spondias spp., processing, quality control, storage.

1'(Trabalho 366-13). Recebido em: 02-10-2013. Aceito para publicação em: 30-04-2014.

${ }^{2}$ Tecnólogo em Alimentos, M.Sc. Eng. Agrícola, Unive. Fed. de Campina Grande. Campina Grande-PB. E-mail: emanuel.oliveira16@, gmail.com; dyego.csantos@gmail.com

${ }^{3}$ Eng. Química, D.Sc. Eng. de Processos, Prof. Adjunta da Univ. Fed. de Campina Grande, Campina Grande-PB. E-mail: anatrindade@, deag.ufcg.edu.br

${ }^{4}$ Eng. Agrícola, D.Sc. Eng. de Alimentos, Prof ${ }^{a}$ Associada da Univ. Fed. de Campina Grande, Campina Grande-PB. E-mail: josi@gmail.com 


\section{INTRODUÇÃO}

O umbu-cajá (Spondias spp.) é um fruto nativo do Nordeste brasileiro que apresenta características sensoriais intermediárias entre o cajá ( $S$. mombin L.) e o umbu (S. tuberosa Camara). Apesar de muito apreciado nos locais onde ocorre, constituindo-se em uma importante fonte de renda em períodos de safra, ao ser comercializado em feiras livres e às margens de rodovias, tem-se observado que o potencial econômico dessa fruta ainda é pouco explorado. Como alternativa para agregar valor aos frutos da umbu-cajazeira, de modo a ampliar sua oferta e consumo, inclusive em outras regiões do País, sugere-se o processamento para desenvolvimento de geleias, uma vez que, dentro do segmento de conservas de frutas, esse produto é um dos que mais se destacam.

As geleias constituem-se em importante alternativa para o processamento, aproveitamento e consumo de frutas. Elas são produtos de umidade intermediária preparadas com polpa de frutas, açúcar, pectina, ácido e outros ingredientes, que permitem sua conservação por um período prolongado (BASU et al., 2013). A pectina empregada na elaboração de geleias tradicionais deve apresentar alto teor de metoxilação (ATM). De acordo com Javanmard et al. (2012), o mecanismo de geleificação da pectina ATM é por interações hidrófobas e pontes de hidrogênio em condições ácidas $(\mathrm{pH}<3,4)$ e baixa atividade de água (cerca de 55\% de açúcar), o que a torna apropriada para ser utilizada em geleias.

No processamento tradicional de geleias, todos os ingredientes são misturados em proporções adequadas, e a mistura é concentrada por aplicação de um tratamento térmico para atingir o teor de sólidos solúveis desejado (IGUAL et al., 2013). A concentração a temperaturas elevadas promove considerável estabilidade microbiológica ao produto, reduzindo a carga microbiana e a atividade de água (SILVA et al., 2012), o que possibilita a comercialização das geleias em períodos prolongados. Apesar de certa estabilidade microbiológica, Rababah et al. (2014) destacam que outras características de qualidade, como cor, textura e parâmetros físicos e químicos, podem ser afetadas durante o armazenamento das geleias, tornando-se necessário o estudo da estabilidade química e física de novos produtos alimenticios à base de frutas.

Estudos envolvendo a estabilidade de geleias de uma grande variedade de frutas estão disponíveis na literatura. Santos et al. (2012) e Safdar et al. (2012) armazenaram geleia de cagaita (Eugenia dysenterica DC.) e manga, respectivamente, em condições ambientais, e reportaram boa estabilidade química do produto, sendo observadas algumas alterações significativas, porém pequenas, nos parâmetros físicos e químicos ao longo de 4 e 5 meses de estocagem, respectivamente. Damiani et al. (2012a) desenvolveram geleia mista de araçá (Psidium guineensis Sw.) e marolo (Annona crassiflora Mart.) e verificaram que, apesar de o processamento da geleia ter apresentado resultados globais positivos, ocorreram alterações significativas em parâmetros físicos e químicos durante o armazenamento de 12 meses. Mesquita et al. (2013) investigaram a ocorrência de alterações em parâmetros físicos e químicos em geleia de goiaba adicionada de prebiótico estocadas em condições ambientais por 6 meses e evidenciaram que todas as variáveis estudadas foram afetadas significativamente pelo tempo de armazenamento. Apesar da variedade e diversidade de frutas utilizadas no processamento de geleias, não foram encontrados na literatura consultada estudos abordando o processamento do umbu-cajá para o desenvolvimento desse tipo de produto.

Considerando-se a necessidade de estudos que busquem agregar valor às frutas nativas do Nordeste brasileiro pouco exploradas economicamente, objetivou-se neste trabalho desenvolver geleia tradicional de umbu-cajá, caracterizá-la quanto a parâmetros físicos, químicos, microbiológicos e sensoriais, e avaliar sua estabilidade durante o armazenamento de seis meses em condições ambientais.

\section{MATERIAL E MÉTODOS}

Foram utilizados frutos maduros de umbucajá, safra de maio de 2011, provenientes do município de Patos-PB ( $7^{\circ} 1^{\prime} 32^{\prime \prime}$ sul, $37^{\circ} 16^{\prime} 40^{\prime \prime}$ oeste), pectina de alto teor de metoxilação (ATM) com 150 으 (CP Kelco, EUA) e açúcar cristal obtido no mercado local. Os frutos foram transportados ao laboratório, onde foram selecionados e excluídos os frutos injuriados, sendo os demais lavados em água corrente e sanitizados em solução clorada (100 ppm por 15 minutos). A separação da polpa foi realizada em despolpadeira horizontal da Laboremus, modelo DF-200, utilizando-se de peneira de malha com 2,5 mm para a separação da polpa das sementes e fibras. A polpa foi envasada em sacos de polietileno com capacidade para $500 \mathrm{~g}$, submetida a um congelamento rápido através da imersão em nitrogênio líquido $\left(-196{ }^{\circ} \mathrm{C}\right)$ em botijões criogênicos, com o objetivo principal de preservar suas características nutritivas e sensoriais, e estocadas em freezer à temperatura de 
$-18 \pm 2{ }^{\circ} \mathrm{C}$ até a elaboração da geleia.

Para o processamento, a polpa foi previamente descongelada sob refrigeração a cerca de $4{ }^{\circ} \mathrm{C}$. Posteriormente, corrigiu-se o $\mathrm{pH}$ de 2,9 para 3,2 com bicarbonato de sódio de uso culinário, objetivando-se atingir o $\mathrm{pH}$ ideal para geleificação da pectina (3,0 a $3,2)$. Após a correção do $\mathrm{pH}$, a polpa com $12,5^{\circ} \mathrm{Brix}$ foi diluída com água potável na proporção de $6: 4$ $\mathrm{m} / \mathrm{m}$. Utilizou-se no processamento de $55 \%$ de açúcar cristal, $1 \%$ de pectina ATM e polpa de umbu-cajá diluída para o balanço total de $100 \%$. A concentração de açúcar foi estabelecida com base na legislação brasileira (BRASIL, 1978), que estabelece variação de 50 a $60 \%$ de açúcar em geleias e considerando-se Javanmard et al. (2012) que reportam concentração de açúcar de 55\% como ideal para a geleificação da pectina ATM. Como o umbu-cajá apresentou baixos conteúdos de pectina $(<0,1 \%)$, sua adição foi estabelecida de acordo com o Ministério da Saúde (BRASIL, 2009), que recomenda quantidade suficiente de pectina para se obter o efeito desejado.

A formulação foi submetida à cocção em tacho aberto de aço inoxidável sem camisa de vapor até teor de sólidos solúveis totais de cerca de $68^{\circ}$ Brix. Posteriormente, a geleia foi envasada em recipientes de vidro transparentes previamente esterilizados $\left(\sim 100{ }^{\circ} \mathrm{C}\right.$ por 15 minutos $)$, com capacidade de $185 \mathrm{~mL}$. A geleia envasada foi resfriada por imersão dos potes em água fria clorada (10 ppm) até $24{ }^{\circ} \mathrm{C}$ e submetida às análises físicas, químicas, microbiológicas e sensoriais.

A geleia foi caracterizada quanto aos parâmetros de teor de umidade, sólidos totais por diferença, cinzas, açúcares (redutores em glicose, não redutores em sacarose e totais em glicose), $\mathrm{pH}$, sólidos solúveis totais e acidez total titulável em ácido cítrico (INSTITUTO ADOLFO LUTZ, 2008), ratio pela relação dos sólidos solúveis totais e acidez total titulável (BRASIL, 1986), proteínas, carboidratos totais (AOAC, 2010) e valor calórico (ANVISA, 2005). A atividade de água foi determinada através de leitura da amostra em higrômetro Aqua-Lab, modelo 4TE (Decagon), os parâmetros de textura (extrusão, firmeza e adesividade) foram quantificados em texturômetro universal, modelo TA-XT plus - Textura Analyzer do fabricante Stable Micro Systems equipado com o software Exponent Stable Micro Systems, utilizando-se do probe HDP-FE5 com auxílio do acessório HDP/CAT para análise de extrusão e o probe P-36R, para as análises de firmeza e adesividade, e a cor foi determinada em espectrofotômetro portátil Hunter Lab Mini Scan XE Plus, modelo 4500 L, obtendo-se os parâmetros $\mathrm{L}^{*}, \mathrm{a}^{*}$ e $\mathrm{b}^{*}$, em que $\mathrm{L}^{*}$ define a luminosidade $\left(\mathrm{L}^{*}\right.$
$=0-$ preto, e $L^{*}=100-$ branco) e $a^{*}$ e $b^{*}$ são responsáveis pela cromaticidade $\left(+\mathrm{a}^{*}\right.$ vermelho e $-\mathrm{a}^{*}$ verde; $+\mathrm{b}^{*}$ amarelo e $-\mathrm{b}^{*}$ azul). A partir destes valores, calcularam-se os valores de croma ( $\left.\mathrm{c}^{*}\right)$, que correspondem à saturação ou intensidade da cor, pela fórmula $\mathrm{c}^{*}=\sqrt{\left(\mathrm{a}^{*}\right)^{2}+\left(\mathrm{b}^{*}\right)^{2}}$ e os valores de ângulo de tonalidade (ângulo $\mathrm{h}^{*}$ ), expressa em graus, pela fórmula $h^{*}=\tan ^{-1} b^{*} / a^{*}$.

Os testes microbiológicos consistiram em análises de coliformes totais, utilizando-se do caldo lactosado bile verde brilhante, bile incubado em tubos de ensaio a $35^{\circ} \mathrm{C}$ por $48 \mathrm{~h}$, coliformes termotolerantes em caldo $E$. coli incubado em tubos de ensaio a 45,5 ${ }^{\circ} \mathrm{C}$ por $48 \mathrm{~h}$, bolores e leveduras, usando-se o ágarpadrão para contagem (plate count agar), incubado em placas a $35^{\circ} \mathrm{C}$ por $48 \mathrm{~h}$, Salmonella, utilizandose dos meios de cultuta ágar verde brilhante e ágar Salmonella-Shigella inoculados em estrias e incubados a $35-37{ }^{\circ} \mathrm{C}$ por $24 \mathrm{~h}$, bactérias mesófilas por plaqueamento com uso de ágar-padrão para contagem em placas estéreis incubadas a $35^{\circ} \mathrm{C}$ por 48 h, e para Staphylococcus coagulase positiva utilizouse do método de contagem spread-plate em ágar baird parker (BP), incubado a $35-37^{\circ} \mathrm{C}$ por 48 horas. Ambos os ensaios foram realizados em triplicata, de acordo com os métodos do APHA (2001).

O teste sensorial foi realizado mediante aprovação do Comitê de Ética em Pesquisa da Universidade Estadual da Paraíba (UEPB) sob processo CAAE n 0110.0.133.000-11. A avaliação sensorial foi conduzida logo após a elaboração da geleia com equipe de 40 julgadores não treinados, composta por homens e mulheres com idades variando entre 20 e 59 anos. Aproximadamente 10 g de geleia foi servida a $22{ }^{\circ} \mathrm{C}$ em copo plástico acompanhada de bolacha tipo água e sal, e água mineral para a limpeza do palato. Aplicou-se o teste de aceitação (DUTCOSKY, 2011), usando uma escala hedônica estruturada, mista de nove pontos, com escores variando de 1 (desgostei muitíssimo) a 9 (gostei muitíssimo), com avaliação dos atributos sensoriais de cor, aparência, aroma, consistência, sabor, doçura e impressão global. O índice de aceitabilidade, conforme Equação 1, foi calculado para cada atributo avaliado (GULARTE, 2009). Paralelamente ao teste de aceitação, verificou-se a intenção de compra da geleia com uso de uma escala estruturada de cinco pontos, com escores variando entre 1 (certamente não compraria) e 5 (certamente compraria o produto).

$$
\text { Índice de aceitabilidade }(\%)=\frac{\mathrm{M}}{\mathrm{N}} \times 100
$$


Em que: M - média do somatório dos resultados dos julgadores;

$\mathrm{N}$ - número de pontos utilizados na escala de avaliação.

A geleia foi armazenada à temperatura e umidade relativa aos ambientes de Campina Grande-PB (média anual de $23,25{ }^{\circ} \mathrm{C}$ e $81 \%$, respectivamente), em local limpo, seco e arejado, durante 6 meses. No início da armazenagem (tempo zero) e a cada trinta dias após o processamento, avaliou-se a estabilidade da geleia através das determinações de teor de umidade, sólidos totais, $\mathrm{pH}$, acidez total titulável (\% ácido cítrico), sólidos solúveis totais, ratio, atividade de água, parâmetros de textura (extrusão, firmeza e adesividade) e cor $\left(\mathrm{L}^{*}, \mathrm{a}^{*}, \mathrm{~b}^{*}, \mathrm{c}^{*} \mathrm{e} \mathrm{h}^{*}\right)$.

A análise estatística seguiu um delineamento inteiramente casualizado, com 7 períodos de armazenamento $(0 ; 1 ; 2 ; 3 ; 4 ; 5$ e 6 meses $)$ e três repetições, utilizando-se do programa computacional Assistat versão 7.5 beta. Os dados foram submetidos à análise de variância e à análise de regressão com modelos polinomiais.

\section{RESULTADOS E DISCUSSÃO}

Têm-se na Tabela 1 os valores médios da caracterização física e química da geleia tradicional de umbu-cajá após o processamento. A umidade apresentou-se abaixo do máximo permitido pela legislação brasileira (BRASIL, 1978), que é de $38 \%$, estando semelhante aos valores reportados por Santos et al. (2012) em geleia de cagaita $(35,21 \%)$, Damiani et al. (2012a) em geleia mista de araçá com marolo $(35,89)$ e Damiani et al. (2012b) em geleia de araçá $(34,45 \%)$. A geleia de umbu-cajá apresentou baixos conteúdos de cinzas e proteínas, e teor de carboidratos superior a $60 \%$, o que contribuiu para o valor calórico de cerca de $255 \mathrm{kcal} / 100 \mathrm{~g}$. Em estudos similares, Barcia et al. (2010) e Dessimoni-Pinto et al. (2011) também reportaram baixos teores de cinzas e proteínas em geleias tradicionais de jambolão e cascas de jabuticaba, respectivamente, e valores energéticos superiores a $250 \mathrm{kcal} / 100 \mathrm{~g}$, estando de acordo com os dados desta pesquisa.

O teor de sólidos solúveis totais está semelhante ao de Chauhan et al. (2013) ao estudarem geleias de polpa de coco e Ndabikunze et al. (2011) ao desenvolverem geleias com polpa de Uapaca kirkiana. Os autores citados reportaram valores de sólidos solúveis dentro da faixa de 68,5 a $68,8^{\circ}$ Brix. A acidez total titulável apresentou valor inferior a $0,8 \%$, que é o valor máximo estipulado por Jackix
(1988) em geleias de frutas (0,3 a 0,8\%). De acordo com Freitas et al. (2008), a acidez excessiva pode causar desidratação e hidrólise da pectina, resultando em sinérese. A relação SST/ATT (ratio), ou sensação de doçura, foi superior a 140 devido ao elevado teor de sólidos solúveis e à baixa acidez total, estando próximo ao ratio reportado por Caetano et al. (2012) em geleia elaborada com suco de acerola, com valor de 138,71 . O pH apresentou-se dentro da faixa de 3,0 a 3,2 reportada por Freitas et al. (2008). Valores de $\mathrm{pH}$ abaixo ou acima dessa faixa diminuem a firmeza do produto final, sendo que com $\mathrm{pH}$ abaixo de 3,0 ocorre tendência a sinérese (JACKIX, 1988). Valores de $\mathrm{pH}$ dentro da faixa citada também foram encontrados em geleias de coco (CHAUHAN et al., 2013) e mamão com araçá-boi (VIANA et al., 2012).

A atividade de água $\left(\mathrm{a}_{\mathrm{w}}\right)$ foi inferior a 0,8 devido à adição de grande quantidade de açúcar, corroborando os dados de Assis et al. (2007), que reportaram em geleias de caju $\mathrm{a}_{\mathrm{w}}$ variando entre 0,77 a 0,78 . Em relação às porcentagens de açúcares, houve predomínio dos açúcares redutores em relação aos açúcares não redutores, estando relacionado à etapa de cocção da geleia. Assis et al. (2007) relataram que, durante o processamento e o cozimento, a sacarose, na presença de ácido, sofre uma hidrólise (inversão) na qual açúcares redutores (glicose e frutose) são formados, sendo que a taxa de inversão depende da temperatura, do tempo de aquecimento e do pH da solução (mistura).

A geleia tradicional de umbu-cajá apresentou baixa luminosidade, o que está relacionado à síntese de compostos de coloração escura pelas reações de escurecimento (CHAUHAN et al., 2013) e de caramelização, ocorridas durante o processo de concentração da geleia (DAMIANI et al., 2008). Houve predomínio da coloração amarela $\left(+b^{*}\right)$ em relação à vermelha $\left(+\mathrm{a}^{*}\right)$, apesar da caramelização da sacarose durante a cocção. Os valores de $+a^{*}$ e $+b^{*}$ da geleia de umbu-cajá foram semelhantes aos dados de Damiani et al. (2008) ao estudarem geleias de manga formuladas com diferentes níveis de cascas em substituição à polpa. $\mathrm{O}$ ângulo de tonalidade $(\mathrm{h} *)$ e o croma ( $\mathrm{c}^{*}$ ) apresentaram-se próximos aos de Igual et al. (2013) ao desenvolverem geleias de toranja. Os autores citados reportaram $\mathrm{h}^{*}$ variando de 34 a $38 \mathrm{e}$ $c^{*}$ oscilando entre 17 e 21.

A firmeza de quase $7 \mathrm{~N}$ deve-se à formação de uma estrutura densa e rígida devido à gelatinização da pectina. Esse valor é superior à firmeza encontrada por Rababah et al. (2014) em geleias de cereja (1,70 a 1,77 N) e inferior aos dados de Javanmard et al. (2012) em geleias de manga (43,63 a 123,92 N). Ressalta-se que a firmeza depende da porcentagem 
de pectina utilizada na formulação da geleia e da concentração do produto durante a etapa de cocção. A extrusão foi de quase $33 \mathrm{~N}$, já a adesividade apresentou-se dentro da faixa encontrada por Javanmard et al. (2012) em geleias de manga (-1,88 a $-9,5 \mathrm{~N})$.

Estão apresentados na Tabela 2 os resultados das análises microbiológicas da geleia tradicional de umbu-cajá. Não foram verificadas contagens dos microrganismos pesquisados, atestando que o processamento desse produto seguiu as recomendações das Boas Práticas de Fabricação (BPF) e também a efetividade do tratamento térmico empregado. A ausência dos microrganismos na geleia também pode ter sido influenciada pela composição química e pelas características intrínsecas da geleia, a qual apresentou elevado conteúdo de açúcar, $\mathrm{pH}$ ácido e teor elevado de sólidos solúveis (SANTOS et al., 2012). Resultados similares foram reportados por Assis et al. (2007) e Yuyama et al. (2008) em geleias de caju e cubiu (Solanum sessiliflorum Dunal), com ausência dos microrganismos investigados.

De acordo com a Tabela 3, a geleia de umbucajá apresentou boa aceitação, em todos os atributos investigados, apresentando aceitabilidade superior a $70 \%$, o que segundo Dutcosky (2011) e Gularte (2009) é a porcentagem mínima para que um produto seja considerado aceito, em termos de suas características sensoriais. Índices de aceitabilidade superiores a 70\% também foram reportados por Santos et al. (2012) e Caetano et al. (2012) ao estudarem a aceitabilidade de geleias de cagaita e acerola, respectivamente. Todos os atributos avaliados no teste de aceitabilidade obtiveram escores entre 6,83 e 7,55, sendo a maior nota atribuída para a aparência, e a menor, para a doçura, uma vez que os provadores relataram sabor doce intenso. Pereira et al. (2011) encontraram escores variando de 6,08 a 7,52 ao avaliarem o perfil sensorial de geleias de marmelo 'Japonês' com diferentes concentrações de sólidos solúveis totais, estando próximos aos valores deste estudo. Já Freitas et al. (2008) relataram escores oscilando entre 4,95 a 7,70 ao avaliarem a aceitabilidade de geleias de gabiroba adicionadas de diferentes concentrações de ácido cítrico.

Quanto à intenção de compra (Figura 1), $67,5 \%$ da frequência de respostas estava entre os escores 4 (provavelmente compraria) e 5 (certamente compraria), o que evidencia potencial mercadológico da geleia tradicional de umbu-cajá. Viana et al. (2012), ao avaliarem sensorialmente geleias de mamão com araçá-boi, também reportaram frequência de resposta favorável à intenção de compra, com $74 \%$ dos julgadores indicando que comprariam a formulação de geleia formulada com $70 \%$ de mamão e $30 \%$ de araçá-boi. Pereira et al. (2011) desenvolveram geleias de marmelo 'Japonês' com diferentes concentrações de sólidos solúveis totais e verificaram frequência de respostas de 68 e $66 \%$ para as geleias com 68 e 70 ${ }^{\circ}$ Brix, respectivamente, sendo semelhantes à resposta encontrada para a geleia de umbu-cajá.

A Figura 2 apresenta os dados da estabilidade química ao longo do armazenamento da geleia tradicional de umbu-cajá em condições ambientais. O teor de umidade revelou tendência de redução não significativa $(\mathrm{p}>0,01)$ até o quarto mês de estocagem, seguido de acréscimo até ao final do período de armazenamento. $\mathrm{O}$ comportamento estatisticamente estável da umidade deve-se provavelmente à não interação do produto com o meio ambiente, devido à utilização de embalagens adequadas e seu eficiente sistema de fechamento (ASSIS et al., 2007). Os sólidos totais tiveram comportamento oposto ao da umidade, o que era esperado, aumentando não significativamente $(p>0,01)$ até o quarto mês de armazenamento, seguido de queda até o sexto mês de estocagem. Ndabikunze et al. (2011), ao armazenarem geleia de U. kirkiana elaborada com pectina comercial, verificaram comportamento semelhante, com ligeira queda não significativa da umidade, seguida de elevação desse teor com o decorrer da estocagem.

Houve aumento do $\mathrm{pH}(\mathrm{p}<0,01)$ até o quinto mês de armazenamento, seguido de ligeira queda desse valor ao final da estocagem, estando relacionado com a redução da acidez em igual período $(\mathrm{p}<0,01)$ com posterior elevação ao término do armazenamento da geleia. A partir do primeiro mês de estocagem, o pH manteve-se superior a 3,2, o que pode afetar a firmeza da geleia (JACKIX, 1988; FREITAS et al., 2008) com degradação da pectina e sinérese do produto, se as condições de armazenagem permitirem. Entretanto, neste trabalho, não foi visualizada sinérese na geleia de umbu-cajá, o que pode estar relacionada à acidez que permaneceu inferior a $0,8 \%$ em todos os períodos de estocagem (JACKIX, 1988). Essas observações estão em conformidade com os resultados de Damiani et al. (2012b), que também reportaram aumento do pH e redução nos valores de acidez com o armazenamento de geleia de araçá. Os sólidos solúveis totais oscilaram durante todo o armazenamento, contudo apresentando tendência significativa $(p<0,01)$ de elevação ao final da estocagem com aumento de cerca de 3\% em relação ao valor inicial, o que pode ser devido à concentração dos açúcares, uma vez que houve tendência de redução da umidade da geleia, apesar de não significativa. Essa observação 
corrobora Safdar et al. (2012) que, ao estocarem geleias de manga também reportaram tendência de elevação dos sólidos solúveis totais ao final do armazenamento.

Os valores de ratio (relação SST/ATT) aumentaram até o quarto mês de estocagem $(\mathrm{p}<0,01)$, sendo verificada queda ao final do armazenamento, contudo permanecendo mais de $10 \%$ superior em relação ao valor inicial. Isso sugere que a sensação de doçura aumentou consideravelmente, podendo inclusive afetar a qualidade sensorial do produto, uma vez que, na análise sensorial realizada no tempo inicial (Tabela 3), o atributo de doçura foi o que obteve o menor escore de avaliação, onde os provadores reportaram que a amostra apresentava sabor doce intenso. Entretanto, apenas uma investigação sensorial ao longo da estocagem poderia ratificar essa hipótese. Esses resultados estão de acordo com Barcia et al. (2010), que ao estocarem geleia tradicional de jambolão em condições ambientais, também verificaram elevação do ratio ao final do período de armazenagem, com elevação de mais de $9 \%$. Houve redução gradual da $a_{w}$ ao longo do armazenamento, estando provavelmente correlacionado com a redução da umidade da geleia ao final da estocagem. Comportamento semelhante foi relatado por Mesquita et al. (2013), ao armazenarem geleia de goiaba em condições ambientais por 6 meses. Os autores citados evidenciaram redução significativa na $\mathrm{a}_{\mathrm{w}}$ durante a estocagem da geleia.

Tem-se na Figura 3 os dados da estabilidade da cor e da textura ao longo do armazenamento da geleia tradicional de umbu-cajá em condições ambientais. Os potes com os produtos foram armazenados em prateleiras de laboratório expostos à luz, simulando as condições de comercialização. Houve considerável escurecimento da geleia ao longo da armazenagem, com redução significativa $(\mathrm{p}<0,01)$ da luminosidade $\left(\mathrm{L}^{*}\right)$ em aproximadamente $50 \%$ ao final da estocagem, o que pode estar relacionado ao efeito da luz, uma vez que foi utilizada embalagem de vidro transparente, e a síntese de compostos escuros não enzimáticos produzidos através da reação de Maillard, fenômeno que geralmente ocorre durante o armazenamento prolongado de alimentos. Damiani et al. (2012b) e Chauhan et al. (2013) também reportaram escurecimento ao armazenarem geleias de araçá e coco, respectivamente, com considerável redução da L* ao longo da estocagem. Esse escurecimento afetou a aparência do produto durante a estocagem, todavia não se pode afirmar se isto interfere na preferência dos consumidores, uma vez que não foi realizada análise sensorial ao longo do armazenamento da geleia. As intensidades de vermelho $\left(+a^{*}\right)$ e de amarelo $\left(+b^{*}\right)$ tiveram reduções significativas $(\mathrm{p}<0,01)$ de aproximadamente $18 \%$ e $53 \%$, respectivamente, ao final da estocagem, devido provavelmente à degradação de pigmentos carotenoides e compostos fenólicos, estando similar ao comportamento descrito por Igual et al. (2013) ao estudarem o armazenamento de geleias de toranja, onde foram observados decrescimos nos valores de $+a^{*}$ e $+b^{*}$ com o decorrer da armazenagem. O croma $\left(\mathrm{c}^{*}\right)$ e o ângulo de tonalidade $\left(\mathrm{h}^{*}\right)$ reduziram significativamente $(p<0,01)$ durante toda a estocagem, sendo verificado aos 6 meses de armazenamento diminuição de aproximadamente $41 \%$ e $26 \%$ nesses parâmetros, respectivamente, o que compromete a qualidade visual do produto, uma vez que valores de $c^{*}$ elevados indicam geleia com coloração mais viva, sendo mais atrativas à compra, enquanto o $\mathrm{h}^{*}$ indica a cor perceptível da geleia. Ambos os parâmetros foram reduzidos devido à degradações de pigmentos (carotenoides e flavonoides) que fazem com que os valores de $+\mathrm{a}^{*}$ $\mathrm{e}+\mathrm{b}^{*}$ fossem diminuídos, estando em acordo com os dados de Damiani et al. (2012b).

Os parâmetros de textura (extrusão, firmeza e adesividade) foram afetados significativamente $(\mathrm{p}<0,01)$ pelo tempo de armazenamento. A extrusão teve um ligeiro aumento até o quarto mês de estocagem, sendo verificada posterior queda até o sexto mês, com redução de cerca de $36 \%$ em comparação ao tempo inicial. A firmeza aumentou ao longo da estocagem, corroborando Kopjar et al. (2009), que também verificaram aumento da firmeza em geleia tradicional de morango armazenada em condições ambientais e em temperatura controlada de $4{ }^{\circ} \mathrm{C}$. Ao final da estocagem, a firmeza estava dentro da faixa $(43,63$ a 123,92 N) reportada por Javanmard et al. (2012) em geleias de manga. Como há uma expectativa do consumidor em relação à consistência de geleias, que deve ser um produto que mantém a forma do recipiente onde está inserido, de textura suave e sem grandes resistências ao corte, o aumento da firmeza do produto com o tempo de armazenagem poderia afetar essas características com perda de qualidade sensorial. Houve redução da adesividade até o quinto mês de estocagem, sendo verificado ligeiro aumento ao final do armazenamento, o que pode estar correlacionado com a elevação dos sólidos solúveis da geleia tradicional ao final da estocagem. 
TABELA 1- Caracterização física e química da geleia tradicional de umbu-cajá após processamento

\begin{tabular}{lclc}
\hline \multicolumn{1}{c}{ Parâmetro } & Valor médio & \multicolumn{1}{c}{ Parâmetro } & Valor médio \\
\hline Umidade (\%) & $35,51 \pm 0,82$ & Açúcares totais (\%) & $59,30 \pm 1,19$ \\
Sólidos totais (\%) & $64,49 \pm 0,82$ & Açúcares redutores (\%) & $42,77 \pm 0,94$ \\
Cinzas (\%) & $0,40 \pm 0,13$ & Açúcares não redutores (\%) & $15,71 \pm 0,30$ \\
Proteína (\%) & $0,25 \pm 0,01$ & Luminosidade (L*) & $12,24 \pm 0,04$ \\
Carboidratos totais (\%) & $63,84 \pm 0,78$ & Intensidade de vermelho (a*) & $12,08 \pm 0,10$ \\
Calorias (Kcal/100 g) & $256,35 \pm 3,16$ & Intensidade de amarelo (b*) & $20,17 \pm 0,13$ \\
Sólidos solúveis totais ( ${ }^{*}$ Brix) & $68,47 \pm 0,00$ & Croma (c*) & $23,51 \pm 0,14$ \\
Acidez total titulável (\%) & $0,47 \pm 0,01$ & Angulo de tonalidade (h*) & $59,08 \pm 0,02$ \\
Ratio $(\mathrm{SST} /$ ATT) & $145,33 \pm 2,38$ & Extrusão (N) & $32,63 \pm 1,21$ \\
$\mathrm{pH}$ & $3,11 \pm 0,01$ & Firmeza (N) & $6,71 \pm 1,18$ \\
$\mathrm{a}_{\mathrm{w}}$ & $0,774 \pm 0,001$ & Adesividade (N) & $-2,75 \pm 0,50$ \\
\hline
\end{tabular}

'Média de três repetições para cada parâmetro analisado; SST - Sólidos solúveis totais; ATT - Acidez total titulável; a - atividade de água.

TABELA 2- Valores dos parâmetros microbiológicos da geleia tradicional umbu-cajá.

\begin{tabular}{lclc}
\hline \multicolumn{1}{c}{ Parâmetro } & Resultado & \multicolumn{1}{c}{ Parâmetro } & Resultado \\
\hline Bolores e leveduras (UFC/g) & $<1,0 \times 10^{1}$ & Staphylococcus coagulase positiva (UFC/g) & $<1,0 \times 10^{1}$ \\
Coliformes a $35^{\circ} \mathrm{C}$ & $<3,0$ & Bactérias mesófilas (UFC/g) & $<1,0 \times 10^{1}$ \\
Coliformes a $45^{\circ} \mathrm{C}$ & $<3,0$ & Salmonella & Ausência \\
\hline
\end{tabular}

NMP - Número mais provável; UFC - Unidades formadoras de colônias.

TABELA 3- Valores médios das notas e aceitabilidade da geleia tradicional de umbu-cajá logo após sua elaboração.

\begin{tabular}{lcc}
\hline \multicolumn{1}{c}{ Atributo } & Média das notas & Aceitabilidade (\%) \\
\hline Sabor & $7,23 \pm 1,29$ & 80,33 \\
Aparência & $7,55 \pm 1,30$ & 83,89 \\
Aroma & $7,28 \pm 1,32$ & 80,89 \\
Consistência & $7,40 \pm 1,60$ & 82,22 \\
Cor & $7,33 \pm 1,29$ & 81,44 \\
Doçura & $6,83 \pm 1,53$ & 75,89 \\
Impressão global & $7,33 \pm 1,47$ & 81,44 \\
\hline
\end{tabular}

Descritores da análise sensorial com pontuação variando entre (1) desgostei muitíssimo e (9) gostei muitíssimo. (Obs.: Teste conduzido com 40 provadores).

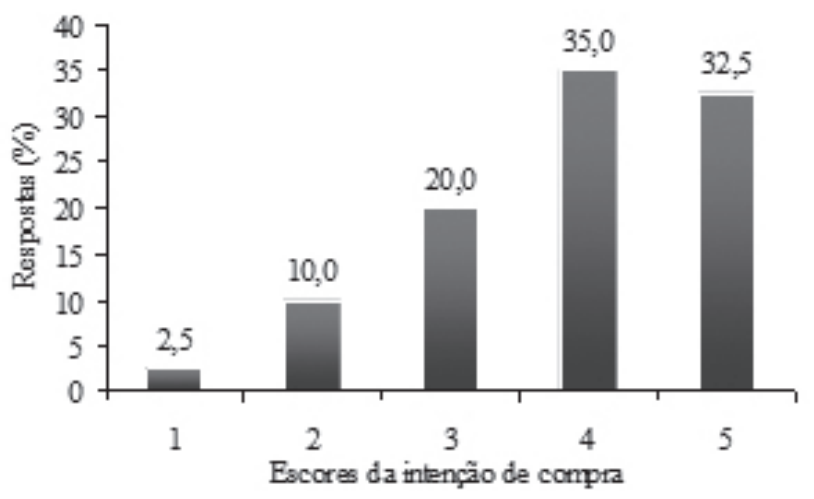

FIGURA 1- Distribuição da frequência de intenção de compra da geleia tradicional de umbu-cajá logo após a sua elaboração (Escores variando de 1-certamente eu não compraria a 5-certamente eu compraria). 

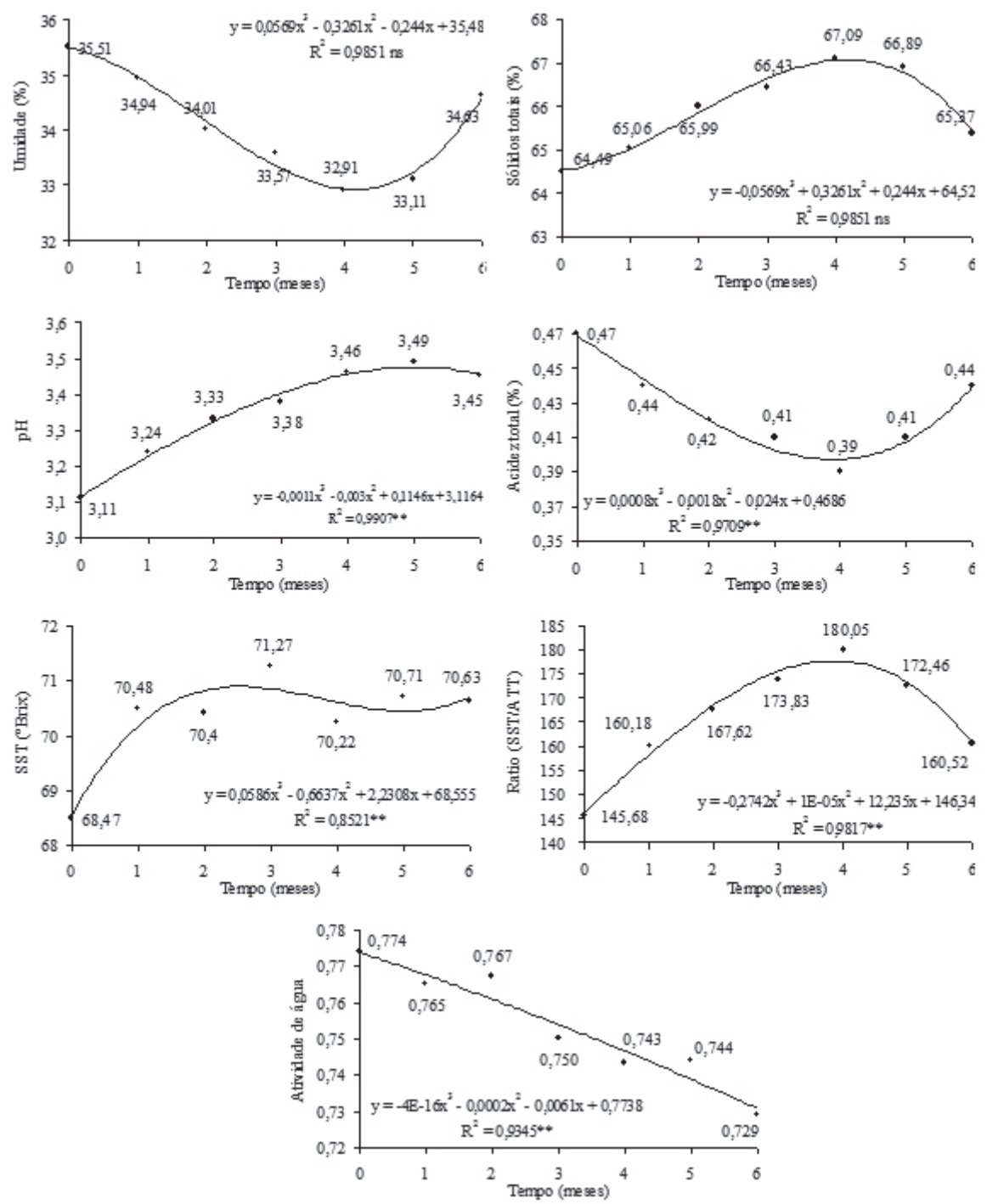

FIGURA 2-Estabilidade dos parâmetros químicos durante o armazenamento por seis meses em condições ambientais da geleia tradicional de umbu-cajá ( ${ }^{\text {ns }}$ não significativo; ${ }^{* *}$ significativo a $1 \%$ de probabilidade pelo teste $\mathrm{F}$ ). 

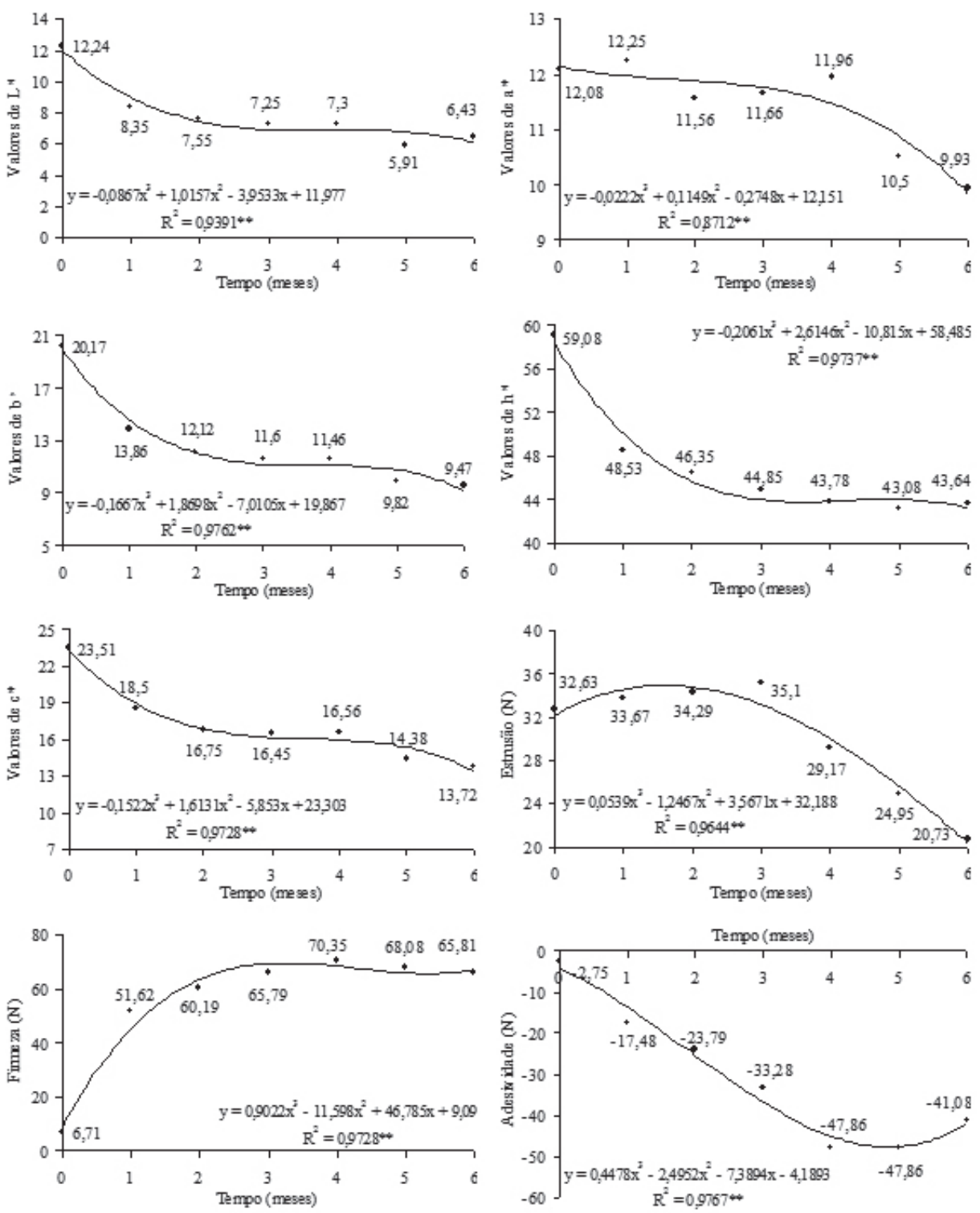

FIGURA 3- Estabilidade dos parâmetros de cor e de textura durante o armazenamento por seis meses em condições ambientais da geleia tradicional de umbu-cajá (**significativo a $1 \%$ de probabilidade pelo teste F). 


\section{CONCLUSÃO}

A geleia de umbu-cajá apresentou-se como um produto calórico, com baixos conteúdos de resíduo mineral e proteínas, e elevado teor de carboidratos. Verificou-se ausência dos microrganismos pesquisados, evidenciando inocuidade e segurança no processamento do produto. Constatou-se elevada aceitabilidade, com índices de aceitação superiores a 70\% para todos os atributos sensoriais de cor, aparência, aroma, consistência, sabor, doçura e impressão global, e intenção de compra de $67,5 \%$, indicando potencial para industrialização e comercialização.

A estocagem da geleia promoveu aumento significativo nos valores de $\mathrm{pH}$, sólidos solúveis totais, ratio e firmeza, e reduções significativas nos parâmetros de acidez, atividade de água, luminosidade $\left(\mathrm{L}^{*}\right)$, intensidades de vermelho $\left(+\mathrm{a}^{*}\right)$ e amarelo $\left(+b^{*}\right)$, croma $\left(c^{*}\right)$, ângulo de tonalidade, extrusão e adesividade. Os valores de umidade e sólidos totais mantiveram-se estatisticamente estáveis durante todo o armazenamento.

O processamento de frutos de umbu-cajá para elaboração de geleia tradicional mostrou-se viável, sendo uma boa alternativa para agregar valor ao fruto, disponibilizando-o em períodos de entressafra e a mercados mais distantes dos centros produtores, apresentando-se desse modo como mais uma opção de renda para pequenos produtores do semiárido brasileiro.

\section{REFERÊNCIAS}

ANVISA - Agência Nacional de Vigilância Sanitária. Rotulagem nutricional obrigatória: manual de orientação às indústrias de Alimentos. 2 ${ }^{\mathrm{a}}$ versão. Brasília: Mistério da Saúde,Universidade de Brasília, 2005. 44 p.

AOAC. Association of Official Analytical Chemists. Official methods of analysis. $18^{\text {th }}$ ed. Washington, 2010. 1094p.

APHA. American Public Health Association. Compendium of Methods for the Microbiological Examination of Foods. $4^{\text {th }}$ ed. Washington, 2001. $676 \mathrm{p}$.

ASSIS, M. M. M.; MAIA, G. A.; FIGUEIREDO, E. A. T.; FIGUEIREDO, R. W.; MONTEIRO, J. C. S. Processamento e estabilidade de geleia de caju. Revista Ciência Agronômica, Fortaleza, v. 38, n. 1, p. 46-51, 2007.
BARCIA, M. T.; MEDINA, A. L.; ZAMBIAZI, R. C. Características físico-químicas e sensoriais de geleias de jambolão. Boletim do Centro de Pesquisa de Processamento de Alimentos, Curitiba, v. 28, n. 1, p. 25-36, 2010.

BASU, S.; SHIVHARE, U. S.; SINGH, T. V. Effect of substitution of stevioside and sucralose on rheological, spectral, color and microstructural characteristics of mango jam. Journal of Food Engineering, Oxford, v. 114, n. 4, p. 465-476, 2013.

BRASIL. Ministério da Saúde. Agência Nacional de Vigilância Sanitária. Resolução de Diretoria Colegiada $n^{\circ} 12$, de 24 de julho de 1978. Normas Técnicas Relativas a Alimentos e Bebidas. Diário Oficial [da] República Federativa do Brasil, Brasília, DF, 1978. Seção I, p.1-75.

BRASIL. Ministério da Agricultura, Pecuária e Abastecimento. Portaria ${ }^{\circ} 76$, de 27 de novembro 1986. Diário Oficial [da] República Federativa do Brasil, Brasília, DF, 1986. Seção I, p.18.152-18.173.

BRASIL. Ministério da Saúde. Agência Nacional de Vigilância Sanitária. Resolução n 28, de 26 de maio de 2009. Atribuição de aditivos alimentares, suas funções e seus limites máximos para geleias (de frutas, de vegetais, de mocotó e com informação nutricional complementar de baixo ou reduzido valor energético). Diário Oficial [da] República Federativa do Brasil, Brasília, DF, 2009. Seção I, p.35.

CAETANO, K.; DAIUTO, E. R.; VIEITES, R. L. Característica físico-química e sensorial de geleia elaborada com polpa e suco de acerola. Brazilian Journal of Food Technology, Campinas, v. 15, n. 3, p. 191-197, 2012.

CHAUHAN, O. P.; ARCHANA, B. S.; SINGH, A.; RAJU, P. S.; BAWA, A. S. Utilization of tender coconut pulp for jam making and its quality evaluation during storage. Food and Bioprocess Technology, Dublin, v. 6, n. 6, p. 1.444-1.449, 2013.

DAMIANI, C.; VILAS BOAS, E. V. B.; SOARES JÚNIOR, M. S.; CALIARI, M.; PAULA, M. L.; PEREIRA, D. E. P.; SILVA, A. G. M. Análise física, sensorial e microbiológica de geleias de manga formuladas com diferentes níveis de cascas em substituição à polpa. Ciência Rural, Santa Maria, v. 38, n. 5, p. 1418-1423, 2008. 
DAMIANI, C.; ASQUIERI, E. R.; LAGE, M. E.; OLIVEIRA, R. A.; SILVA, F. A.; PEREIRA, D. E. P.; VILAS BOAS, E. V. B. Study of the shelf-life of a mixed araça (Psidium guineensis Sw.) and marolo (Annona crassiflora Mart.) jam. Ciência e Tecnologia de Alimentos, Campinas, v. 32, n. 2, p. 334-343, 2012a.

DAMIANI, C.; SILVA, F. A.; ASQUIERI, E. R.; LAGE, M. E.; VILAS BOAS, E. V. B. Antioxidant potential of Psidium guinnensis Sw. jam during storage. Pesquisa Agropecuária Tropical, Goiânia, v. 42, n. 1, p. 90-98, 2012 b.

DESSIMONI-PINTO, N. A. V.; MOREIRA, W. A.; CARDOSO, L. M.; PANTOJA, L. A. Jaboticaba peel for jelly preparation: an alternative technology. Ciência e Tecnologia de Alimentos, Campinas, v. 31, n. 4, p. 864-869, 2011.

DUTCOSKY, S. D. Análise sensorial de alimentos. 3.ed. Curitiba: Editora Universitária Champagnat, 2011. 426p.

FREITAS, J. B.; CÂNDIDO, T. L. N.; SILVA, M. R. Geleia de gabiroba: avaliação da aceitabilidade e características físicas e químicas. Pesquisa Agropecuária Tropical, Goiânia, v. 38, n. 2, p. 87-94, 2008.

GUlarte, M. A. Análise sensorial. Pelotas: Editora Universitária da Universidade Federal de Pelotas, 2009. 66 p.

IGUAL, M.; GARCÍA-MARTÍNEZ, E.; CAMACHO, M. M.; MARTÍNEZ-NAVARRETE, N. Physicochemical and sensorial properties of grapefruit jams as affected by processing. Food and Bioprocess Technology, Dublin, v. 6, n. 1, p. 177-185, 2013.

INSTITUTO ADOLFO LUTZ. Normas analíticas, métodos químicos e físicos para análises de alimentos. 4. ed. São Paulo, 2008. 1.020 p.

JACKIX, M. H. Doces, geleias e frutas em calda. Campinas: Ed. UNICAMP, 1988. 171 p.
JAVANMARD, M.; CHIN, N. L.; MIRHOSSEINI, S. H.; ENDAN, J. Characteristics of gelling agent substituted fruit jam: studies on the textural, optical, physicochemical and sensory properties. International Journal of Food Science and Technology, Oxford, v. 47, n. 9 p. 1808-1818, 2012.

KOPJAR, M.; PILIZOTA, V.; TIBAN, N. N.; SUBARIC, D.; BABIC, J.; ACKAR, D.; SAJDL, M. Strawberry jams: Influence of different pectins on colour and textural properties. Czech Journal of Food Science, Prague, v. 27, n. 1, p. 20-28, 2009.

MESQUITA, K. S.; BORGES, S. V.; CARNEIRO, J. D. S.; MENEZES, C. C.; MARQUES, G. R. Quality alterations during storage of sugar-free guava jam with added prebiotics. Journal of Food Processing and Preservation, London, v. 36, n. 1, p.1-8, 2014.

NDABIKUNZE, B. K.; MASAMBU, B. N.; TIISEKWA, B. P. M.; ISSA-ZACHARIA, A. The production of jam from indigenous fruits using baobab (Adansonia digitata L.) powder as a substitute for commercial pectin. African Journal of Food Science, Lagos, v. 5, n. 3, p. 168-175, 2011.

PEREIRA, G. G.; ALVARENGA, A. A.; ABRAHÃO, E.; PINHEIRO, A. C. M.; OLIVEIRA, A. F.; PIO, R. Avaliação sensorial de geleia de marmelo -'Japonês' em diferentes concentrações de sólidos solúveis totais. Brazilian Journal of Food Technology, Campinas, v. 14, n. 3, p. 226-231, 2011.

RABABAH, T. M.; AL-U'DATT, M.; ALMAHASNEH, M.; YANG, W.; FENG, H.; EREIFEJ, K.; KILANI, I.; ISHMAIS, M. A. Effect of jam processing and storage on phytochemicals and physiochemical properties of cherry at different temperatures. Journal of Food Processing and Preservation, London, v. 36, n. 6, p. 1-8, 2014.

SAFDAR, M. N.; MUMTAZ, A.; HAMEED, T.; SIDDIQUI, N.; KHALIL, S.; AMJAD, M. Storage studies of jam prepared from different mango varieties. Pakistan Journal of Nutrition, Faisalabad, v. 11, n. 7, p. 555-561, 2012. 
SANTOS, P. R. G.; CARDOSO, L. M.; BEDETTI, S. F.; HAMACECK, F. R.; MOREIRA, A. V. B.; MARTINO, H. S. D.; PINHEIRO-SANT'ANA, H. M. Geleia de cagaita (Eugenia dysenterica DC.): desenvolvimento, caracterização microbiológica, sensorial, química e estudo da estabilidade. Revista do Instituto Adolfo Lutz, São Paulo, v. 71, n. 2, p. 281-290, 2012.

SILVA, I. G.; CORREIA, A. F. K.; BIGARAN, J. T.; BAPTISTA, C. P.; CARMO, L. F.; SPOTO, M. H. F. Estudo de caracterização do fruto cambuci [Campomanesia phaea (O. Berg.) Landrum] e sua aplicação no processamento de geleia. Boletim do Centro de Pesquisa de Processamento de Alimentos, Curitiba, v. 30, n. 1, p. 83-90, 2012.
VIANA, E. S.; JESUS, J. L.; REIS, R. C.; FONSECA, M. D.; SACRAMENTO, C. K. Caracterização físico-química e sensorial de geleia de mamão com araçá-boi. Revista Brasileira de Fruticultura, Jaboticabal, v. 34, n. 4, p. 1154-1164, 2012.

YUYAMA, L.K.O.; PANTOJA, L.; MAEDA, R.N.; AGUIAR, J.P.L.; SILVA, S.B. Desenvolvimento e aceitabilidade de geleia dietética de cubiu (Solanum sessiliflorum Dunal). Ciência e Tecnologia de Alimentos, Campinas, v. 28, n. 4, p. 929-934, 2008 